\title{
Markets Integration and Macroeconomic Dispersion in a Monetary Union
}

\author{
Aurélien Eyquem ${ }^{* *}$ \\ Jean-Christophe Poutineau ${ }^{* * *}$
}

\section{$1 \quad$ Introduction}

The adoption of the euro has had significant effects on goods and financial market integration in the European Monetary Union (EMU) since 1999. Among other studies, Baldwin (2006) shows that the euro led to an increase of bilateral trade flows of goods and services between $5 \%$ and $15 \%$. De Grauwe and Mongelli (2005) and Lane (2006) also document an increase of financial integration among EMU members after the euro was introduced.

This increased market integration is usually thought to imply (i) a greater dispersion of current account balances among participating countries, and (ii) a reduced dispersion of both business cycles and inflation rates. Figure 1 displays the evolution of output gaps and inflation rates dispersion among five major EMU countries (Germany, France, Italy, Spain and Netherlands) based on quarterly data from the OECD Economic Outlook database over the last ten years. Figure 1 indicates that the dispersion of CPI inflation rates rose after 1999 and decreased slightly after peaking in 2001. Meanwhile, the dispersion of output gaps fell slightly after 1999 but shows an upward trend since 2003. Thus, despite a noticeable increase in the dispersion of current account balances (see Blanchard and Giavazzi, 2002), the convergence in business cycles and inflation rates expected from the introduction of the euro is nowhere to be found in the data. ${ }^{1}$

* We would like to thank the editor, two anomynous referees, James Anderson, and Stéphane Auray for insightful comments and suggestions.

** GATE, UMR CNRS 5824, Université de Lyon and Ecole Normale Supérieure de Lyon, 15 Parvis René Descartes, BP 7000, 69342 Lyon Cedex, France. Email: aurelien.eyquem @ens-lyon.fr

*** CREM, UMR CNRS 6211, Université de Rennes 1 and Ecole Normale Supérieure de Cachan, 7 place Hoche 35065 Rennes Cedex, France. Email: jean-christophe.poutineau@univ-rennes1.fr.

1 See Honohan et Lane, 2003; Camacho, 2006 and Lane, 2006 for an extensive analysis of this issue. 
In this paper, we provide a theoretical rationale to this puzzle using a two-country DSGE model with sticky prices, allowing for a systematic investigation of the impact of goods and financial markets integration on the dispersion of business cycles and inflation rates among members of a monetary union. The model combines home bias in final, intermediate, capital goods markets and financial markets imperfections, and shows that an increase of markets integration has little and sometimes positive effects on the dispersion of business cycles and inflations rates in a monetary union.

The model assumes that financial markets are both incomplete and that trade in assets is costly for households. As a consequence, national current account balances play a key role in the external adjustment to idiosyncratic shocks occurring in the monetary union. Under this assumption, a reduction of home bias in goods markets implies an increase in corresponding trade flows, which may increase the volatility of the trade balance and the current account. In turn, the dispersion of business cycles and inflation rates may increase to balance households' external assets position in the long run. This result sheds some light on the puzzle documented in the previous paragraph.
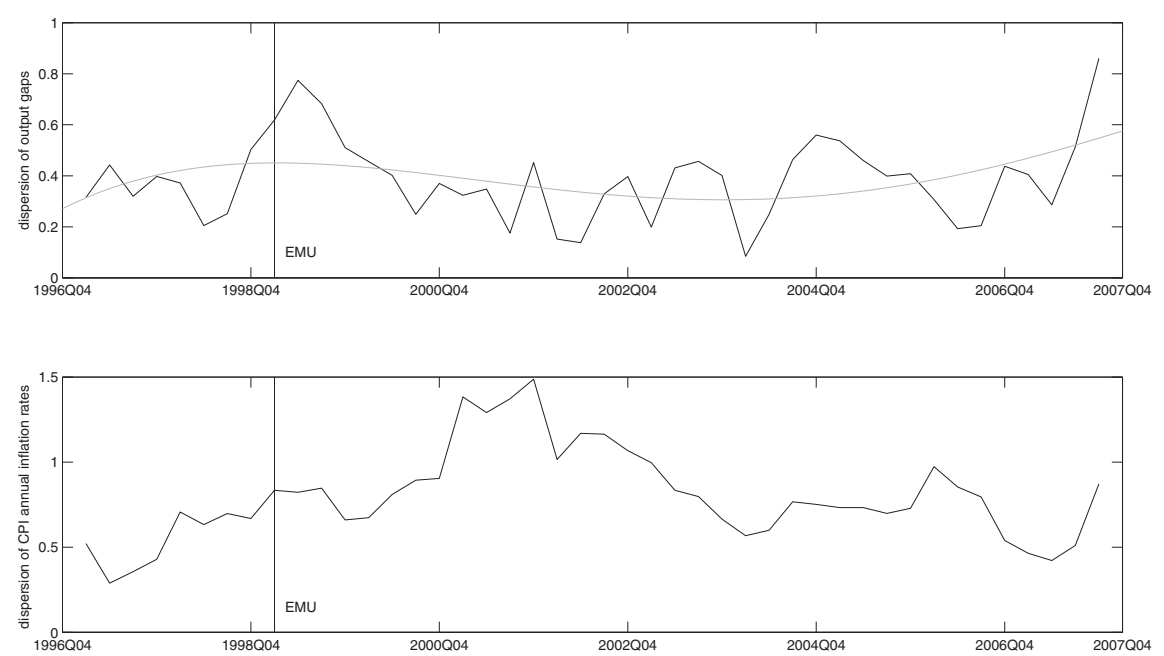

Figure 1: Standard deviation of output gaps and CPI inflation rates between 1997 and 2007 among major EMU members (Germany, France, Italy, Spain and Netherlands).

The major results and the underlying mechanisms detailed in the paper are summarized as follows. 
First, for realistic values of models parameters, a $10 \%$ reduction of home bias in the preferences of households for capital and final goods and services is found to have a negligible and sometimes positive impact on the dispersion of business cycles and inflation rates. As national economies are affected by idiosyncratic shocks, this reduction in home bias increases the volatility of national trade balances as well as the volatility of national current account balances. Debtor households (countries) should thus work harder and earn more with respect to creditor agents to repay their debt and meet the financial equilibrium in the long run. On the other hand, creditor households (countries) face opposite incentives, which triggers an increase of the dispersion of business cycles, and sometimes of country-level inflation rates through general equilibrium linkages.

Second, a $10 \%$ reduction of home bias in the preferences of final goods producers leads to an opposite outcome. This change in production technologies improves the homogeneity of both final goods compositions and producer prices in the monetary union. The macroeconomic transmission of idiosyncratic shocks thus becomes more symmetric, which dampens the need for external adjustment through current account fluctuations, thereby significantly reducing the dispersion of business cycles and inflation rates.

Finally, the paper investigates the impact of a deepening of financial markets integration, modelled as a reduction of intermediation costs bearing on assets transactions. It is found to increase the volatility of national current account balances and thus produces effects that are similar to those stemming from a reduction of home bias in households preferences for capital and final goods and services, i.e. an increase of the dispersion of business cycles and inflation rates.

Assuming that home bias in agents preferences is a good proxy for the degree of goods market fragmentation and that the level of financial intermediation costs is a good proxy for the degree of financial markets segmentation, our results can be interpreted as follows. A deeper integration of intermediate goods markets leads to standard effects by jointly reducing the dispersion business cycles and inflation rates, while a deeper integration of capital goods, final goods and financial markets increases the dispersion of business cycles and inflation rates among participating countries of a monetary union, which may explain the lack of significant macroeconomic convergence since 1999 in the EMU.

The paper is organized as follows. Section 2 describes the model. Section 3 investigates the dynamic properties of the model after asymmetric productivity or public spending shocks. Section 4 analyzes the impact of a deeper integration of goods and financial markets on the dispersion of business cycles and inflation rates. Section 5 evaluates the robustness of the results. Section 6 offers concluding remarks. 


\section{A two-country monetary union}

We lay out a two-country DGSE model of a monetary union. Each country is populated by $(i)$ a unit mass of households, that consume, supply labor, trade financial claims, accumulate physical capital and own national firms, (ii) a government, (iii) a firm that produces and sells an intermediate good on competitive markets $(i v)$ a unit mass of firms producing and selling imperfectly substitutable varieties of final goods and services on monopolistic competition markets. At the union level, a common Central Bank controls the nominal interest rate of the monetary union. ${ }^{2}$

\subsection{Households}

Each country $i \in\{h, f\}$ is populated by a unit mass of households with infinite life. The representative household $j \in[0,1]$ of country $i$ maximizes its welfare subject to a budget constraint and a transversality condition with respect to the accumulation of financial claims. In this budget constraint an additional term, $A C_{t}^{i}(j)$, represents the financial intermediation costs,

$$
A C_{t}^{i}(j)=\frac{\chi}{2}\left(B_{t+1}^{i}(j)-B^{i}(j)\right)
$$

In this expression, $B_{t}^{i}(j)$ is the quantity of one-period bond, held by agent $j$ from country $i$ at the end of $t-1$ that earns a nominal interest rate of $R_{t}$ between $t-1$ and $t . B^{i}(j)$ is the amount of bonds held by agent $j$ in the steady state.

The first order conditions lead to a standard labor supply function,

$$
N_{t}^{i}(j)^{\psi}=W_{t}^{i} P_{t}^{i} C_{t}^{i}(j)^{\rho},
$$

a modified Euler condition,

$$
\beta R_{t+1}^{i} E_{t}\left\{\frac{P_{t}^{i} C_{t}^{i}(j)^{\rho}}{P_{t+1}^{i} C_{t+1}^{i}(j)^{\rho}}\right\}=1
$$

and a no-arbitrage condition describing the choice between bonds and physical capital,

$$
E_{t}\left\{\frac{P_{t+1}^{i}}{P_{t}^{i}}\left(\frac{Z_{t+1}^{i}}{P_{t+1}^{i}}+Q_{t+1}^{i}(j)-\delta\right)\right\}=Q_{t}^{i}(j) R_{t+1}^{i},
$$

where $R_{t+1}^{i}=\frac{R_{t+1}}{1+\chi P_{i, t}\left(B_{t+1}^{i}(j)-B^{i}(j)\right)}$, and where $Q_{t}^{i}$ is Tobin's $q \cdot{ }^{3}$ The modified Euler condition shows that the real interest rate that determines households' con-

2 Since most of these asumptions are standard, the model is detailled in appendix A.

3 The presence of $Q_{t}^{i}(j)$ in this relation is due to the presence of adjustment costs on physical capital accumulation. 
sumption profile over time is higher (respectively lower) for debtor (resp. creditor) households. This specification of portfolio intermediation costs $(i)$ allows to pin down a unique steady state (see Schmitt-Grohé and Uribe, 2003) and (ii) offers an intuitive measure of the degree of financial markets integration, $\chi{ }^{4}$

We assume that agents preferences are biased towards national goods and services, so that consumption bundles are,

$$
C_{t}^{i}(j)=\left[\left(1-\alpha_{i}\right)^{\frac{1}{\mu}}\left[\int_{0}^{1} C_{h, t}^{i}(k, j)^{\frac{\theta-1}{\theta}} d k\right]^{\frac{\theta(\mu-1)}{\mu(\theta-1)}}+\left(\alpha_{i}\right)^{\frac{1}{\mu}}\left[\int_{0}^{1} C_{f, t}^{i}(k, j)^{\frac{\theta-1}{\theta}} d k\right]^{\frac{\theta(\mu-1)}{\mu(\theta-1)}}\right]^{\frac{\mu}{\mu-1}},
$$

and that final goods producers do not discriminate between national markets, so that the law of one price holds. Consumption prices are thus,

$$
P_{t}^{i}=\left[\left(1-\alpha_{i}\right)\left[\int_{0}^{1} P_{h, t}(k)^{1-\theta} d k\right]^{\frac{1-\mu}{1-\theta}}+\left(\alpha_{i}\right)\left[\int_{0}^{1} P_{f, t}(k)^{1-\theta} d k\right]^{\frac{1-\mu}{1-\theta}}\right]^{\frac{1}{1-\mu}} .
$$

In these expressions, $P_{i, t}(k)$ is the price of a variety $k$ produced in country $i$ and $\left(1-\alpha_{i}\right) \in\left[\frac{1}{2}, 1\right]$ is the bias towards national final goods and services of households of country $i$. Thus, $2 \alpha_{i}$ is a good approximation of the degree of mutual trade openness on this market (see Corsetti, 2006). The parameter $\mu \geq 1$ represents the elasticity of substitution between the final goods of country $h$ and $f$ and $\theta>1$ represents the elasticity of substitution between varieties of similar origin. In appendix B, we show that home bias in private consumption and iceberg shipping costs specifications are closely related. ${ }^{5}$

The definition of investment bundles is very close to the definition of private consumption bundles, but (potentially) differs in the degree of home bias, denoted by $\left(1-\varphi_{i}\right) \in\left[\frac{1}{2}, 1\right]$. Finally, the aggregate investment of household $j, I_{t}^{i}(j)$, evolves according to,

4 The assumption of incomplete financial markets is indeed known to generate a unit root on net foreign assets. Temporary shocks thus imply permanent wealth transfers. The introduction of portfolio intermediation costs thus allows pin down a unique steady state and to neutralize this shortcoming in the linear dynamics of the model.

5 The relation between iceberg costs and home bias is positive and strictly monotonic (see appendix B), i.e. lower transportation costs are equivalent to a lower level of home bias in private consumption. This relation is clearly consistent with values found in the empirical literature regarding the level of transportation costs and the level of trade openness, that relates closely to home bias in private consumption in our framework (see Coeurdacier, 2008). 


$$
I_{t}^{i}(j)=K_{t+1}^{i}(j)-(1-\delta) K_{t}^{i}(j),
$$

where $K_{t+1}^{i}(j)$ is its stock of capital at the end of period $t$.

\subsection{Governments}

National governments impose a proportional tax $\tau$ on final goods producers' profits to compensate the distortions implied by monopolistic competition on this market. ${ }^{6}$ The level of public spending $G_{t}^{i}$ is exogenous and fully biased towards national final goods. The amount of public spending is financed by the proportional tax and by a lump-sum tax paid by households. The constraint faced by the government of country $i \in\{h, f\}$ thus writes,

$$
\int_{0}^{1} T_{t}^{i}(j) d j+\tau \int_{0}^{1} P_{i, t}(k) Y_{t}^{i}(k) d k=P_{i, t} G_{t}^{i}
$$

\section{$2.3 \quad$ Firms}

Each country $i \in\{h, f\}$ is specialized in the production of an homogenous intermediate good. Given the level of productivity $A_{t}^{i}$, the firm that produces the intermediate good in country $i$ combines national labor $L_{t}^{i}$ with the aggregate level of capital available in the economy $K_{t}^{i}=\int_{0}^{1} K_{t}^{i}(j) d j$ to produce the quantity $X_{t}^{i}$ of intermediate good according to,

$$
X_{t}^{i}=A_{t}^{i}\left(K_{t}^{i}\right)^{\omega}\left(L_{t}^{i}\right)^{1-\omega} .
$$

The unit price of this good $P_{x, t}^{i}$ equates its marginal production cost,

$$
P_{x, t}^{i}=\frac{\left(Z_{t}^{i}\right)^{\omega}\left(W_{t}^{i}\right)^{1-\omega}}{\omega^{\omega}(1-\omega)^{1-\omega} A_{t}^{i}} .
$$

In each country $i \in\{h, f\}$ a unit mass of firms combines domestic and foreign intermediate goods to produce a unit mass of varieties $k \in[0,1]$ of final goods and services. Each firm supplies an amount $Y_{t}^{i}(k)$ of variety $k$ on a monopolistic competition market using the following production function,

$$
Y_{t}^{i}(k)=\left[\left(1-\gamma_{i}\right)^{\frac{1}{\phi}} X_{h, t}^{i}(k)^{\frac{\phi-1}{\phi}}+\left(\gamma_{i}\right)^{\frac{1}{\phi}} X_{f, t}^{i}(k)^{\frac{\phi-1}{\phi}}\right]^{\frac{\phi}{\phi-1}} .
$$

Here, $\left(1-\gamma_{i}\right) \in\left[\frac{1}{2}, 1\right]$ is the national bias towards national intermediate goods, $\phi \geq 1$ is the elasticity of substitution between domestic and for-

6 This assumption restores the efficiency of resources allocation (Benigno and Woodford, 2005). 
eign intermediate goods and $X_{h, t}^{i}(k)$ and $X_{f, t}^{i}(k)$ are the demands in intermediate goods of firm $k$ in country $i$. The marginal cost is the same across varieties,

$$
M C_{t}^{i}(k)=M C_{t}^{i}=\left[\left(1-\gamma_{i}\right)\left(P_{x, t}^{h}\right)^{1-\phi}+\left(\gamma_{i}\right)^{\frac{1}{\phi}}\left(P_{x, t}^{f}\right)^{1-\phi}\right]^{\frac{1}{1-\phi}} .
$$

Each firm determines its supply of variety $k$ by maximizing its profits, given the total demand for this variety into account. Assuming Calvo (1983) pricing contracts, each firm in country $i$ faces a probability $\left(1-\eta^{i}\right)$ to be allowed to choose a new retail price in the current period and a probability $\eta^{i}$ to keep the price set at the previous period unchanged. These contracts give rise to the following Phillips curve,

$$
\pi_{i, t}=\beta E_{t}\left\{\pi_{i, t+1}\right\}+\frac{\left(1-\eta^{i} \beta\right)\left(1-\eta^{i}\right)}{\eta^{i}}\left(m c_{t}^{i}-p_{i, t}\right), i \in\{h, f\},
$$

describing the log-linear dynamics of the aggregate producer price index inflation rate.

\subsection{Monetary policy}

The Central Bank of the monetary union controls the nominal interest rate according to the monetary rule, ${ }^{7}$

$$
R_{t+1}=\left(1-\rho_{r}\right) R+\rho_{r} R_{t}+\frac{d_{\pi}}{2}\left(\pi_{t}^{h}-\tilde{\pi}_{t}^{h}\right)+\frac{d_{\pi}}{2}\left(\pi_{t}^{f}-\tilde{\pi}_{t}^{f}\right),
$$

where $R-1=\beta^{-1}-1=\delta$ is the steady state real interest rate and $\tilde{\pi}_{t}^{i}$ is the natural level of inflation in country $i$, i.e. the inflation rate under flexible prices and complete financial markets.

\section{Dynamics properties}

This section describes the dynamic consequences of asymmetric productivity and public spending shocks using a log-linear approximation of the model.

7 After testing the impact of several classes of monetary policy rules, it appeared that the type and specification of the rule does not play a key role in our simulations and results. The specification presented here thus approaches as close as possible the monetary policy rule followed by the European Central Bank, such as imposed by its mandate. In particular, one shall note that the case of strict inflation trageting is obtained when $d_{\pi} \rightarrow \infty$ (see Monacelli et Perotti, 2006). 


\subsection{Parametrization}

In the steady state equilibrium, the current account is balanced, i.e. $B^{i}=0$. We impose $A^{i}=A=1, G=\kappa Y, P=1$ and $\tau=(1-\theta)^{-1}$. The Paretoefficient steady state is thus defined by, $R=\beta^{-1}, \frac{Z}{P}=\delta+\beta^{-1}-1$, $W=(1-\omega) \Lambda_{2}^{\frac{\omega}{1-\omega}}, I=\delta K, N=\left[(1-\omega) \Lambda_{1}^{-\rho} \Lambda_{2}^{\frac{\omega-\rho}{1-\omega}}\right]^{\frac{1}{\psi+\rho}}, C=\Lambda_{1} \Lambda_{2}^{\frac{1}{1-\omega}} N, X=Y=\Lambda_{2}^{\frac{\omega}{1-\omega}} N$, and $K=\Lambda_{2}^{\frac{1}{1-\omega}} N$, where $\Lambda_{1}=Z(1-\kappa) \omega^{-1}-\delta$ and $\Lambda_{2}=\omega Z^{-1}$.

We assume that each country of the model is a group of EMU countries, and that each group represents a half of the EMU (see Benigno, 2004). The discount rate is set to $\beta=0.99$ to imply an annualized steady state real interest rate of $4 \%$. The intertemporal elasticity of substitution of labour supply is $\psi^{-1}=0.2$, which lies in the range presented by Canzoneri, Cumby and Diba (2007). Following Beetsma and Jensen (2005), the riskaversion parameter is $\rho=2.5$. We assume that nominal rigidities are symmetric in the monetary union. After Angeloni et al. (2006), the average duration of a price in the economy is equal to 4 quarters, implying $\eta^{h}=\eta^{f}=0.75$. With no empirical study proposing a value for $\chi$ in the EMU, we follow Schmitt-Grohé and Uribe (2003) and impose $\chi=0.0007$. This value corresponds to an annualized portfolio intermediation cost implying an interest rate premium of $0.3 \%$. Public spending represent $20 \%$ of the gross domestic product, implying $\kappa=0.2$. Parameters describing the dynamics of exogenous shocks are $\rho_{a}=0.95, \rho_{g}=0.95, \operatorname{std}\left(\zeta_{t}^{a i}\right)=0.7 \%$ and $\operatorname{std}\left(\zeta_{t}^{g i}\right)=1 \%$. Parameters of the monetary policy rule are $\rho_{r}=0.7$ and $d_{\pi}=1.5$ (see Dellas and Tavlas, 2005). Finally, parameters related to capital accumulation decisions are set according to Bergin, Shin and Tchakarov (2007): the depreciation rate of capital is $\delta=0.025$, the factor elasticity of the physical capital in the production function is $\omega=0.36$, and the adjustment cost on capital accumulation is $\varepsilon=5$.

In the model, goods market integration is approximated by mutual trade openness with respect to capital goods, intermediate goods and final goods. Thus, benchmark values for national biases are computed using the average openness degree of EMU. Using EMU data we get the following values for intra-zone openness: $4.39 \%$ for capital goods, $16.46 \%$ for intermediate goods and $9.22 \%$ for final goods and services. ${ }^{8}$ Since the monetary union considered is closed, and since external trade openness in the EMU is roughly equal to internal trade openness, the degrees of openness should be approximately doubled, i.e. $8.78 \%$ for capital goods, $32.92 \%$ for intermediate goods, and $18.44 \%$ for final goods and services. As $2 \varphi, 2 \gamma$ and $2 \alpha$ approximate these degrees of openness, we set $\varphi=0.0439, \gamma=0.1646$ and

8 Data available at http://sdw.ecb.europa.eu/. 
$\alpha=0.0922$ as benchmark values in the simulations. Furthermore, the elasticity of substitution among final goods of produced in different countries is still an open question in the literature: according to Obstfeld and Rogoff (2000) the literature on international trade generally adopts high values for these elasticities (between 5 and 7), while the DSGE literature adopts lower values (between 1 and 3, as in Backus, Kehoe and Kydland, 1993 or Hairault, 2002). We follow the latter, and set $\mu=2.5$. Finally, we assume that intermediate goods are slightly less substitutable, and set $\phi=1$.

\subsection{Dynamic properties}

Figure 2 displays the Impulse Response Function (IRF) of several macroeconomic variables to a $1 \%$ productivity shock occurring in the domestic economy.
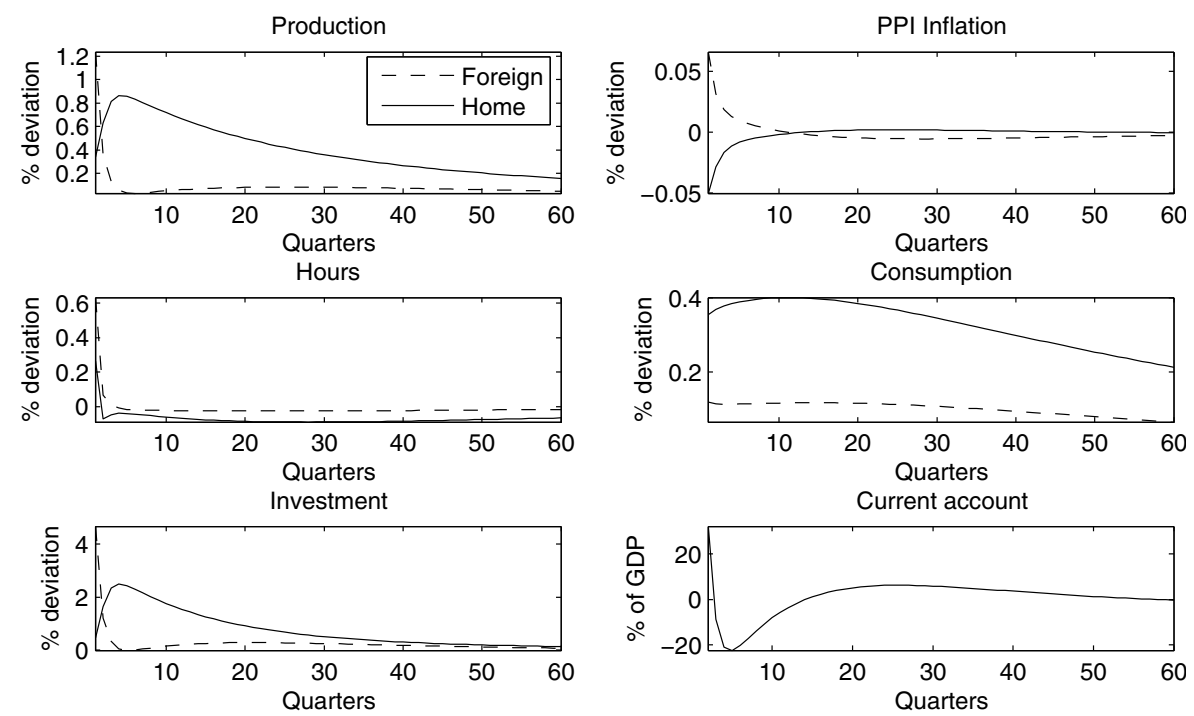

Nominal interest rate
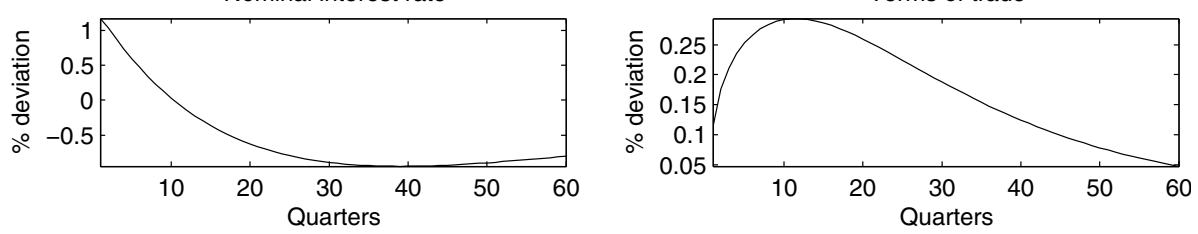

Figure 2: IRFs after a unit productivity innovation in country $\mathrm{h}$.

After the shock in country $h$, two successive effects determine the dynamics of both economies. In the very early periods (4 to 6 quarters), 
there is a significant deflation in country $h$, triggered by lower marginal costs and a significant inflation in country $f$, driven by the increased demand for goods produced in this country. In doing so, the real interest rate increases in country $h$ and drops in country $f$, leading to a sharp rise (but barely persistent) of private investment and production in country $f$ and a much slower increase of investment and production in country $h$. Indeed, in the model a lower real interest rate leads households to invest more intensively, as the relative cost of physical capital declines. For country $h$, the joint rise in investment and production is slower in the early stages because the real interest rate is increased by the deflation. Finally, the sustained increase of capital and production generates a strong inflationary stance in the area, which according to the monetary policy rule, implies an increase of the nominal interest rate in the first periods.

After the 15-20 first quarters, the impact of nominal rigidities on the adjustment vanishes since the persistence of inflation is relatively low in the model. Productivity gains then allow households in country $h$ to increase their consumption level (about $0.4 \%$ almost during 50 quarters) and their production ( $0.6 \%$ to $0.8 \%$ almost during 30 quarters) while keeping their labor supply nearly constant. The transmission of the joint increase of private consumption, capital stock and production to country $f$ occurs through trade linkages on final, intermediate and capital goods markets, which boosts the production of final goods for something like 10 quarters and give rise to a persistent increase of private consumption $(0.1 \%$ for more than 40 quarters). ${ }^{9}$

The external adjustment of economies is reached both through current account and terms-of-trade fluctuations. Given the two-step adjustment described above, the dynamics of the current account, determined by the joint dynamics of private consumptions, productions and investments, should also be decomposed in two subperiods. First, on impact, the current account improves by almost $30 \%$ of quarterly GDP, before exhibiting a deficit of almost $20 \%$ after $15-20$ quarters and returning very slowly to its steady state level under the influence of portfolio intermediation costs. Behind these changes in the current account are changes in the accumulation of assets by households of country $h$, leading them to exhibit a positive international investment position. This positive position in net foreign assets actually reflects the wealth transfer from foreign to home households triggered by productivity gains in country $h$. Finally, the terms-of-trade improve significantly (approximately 0.3\%), driven by inflation differentials (deflation in country $h$ and inflation in country $f$ ).

9 Notice that private consumptions are very smooth and persistent over time, which is directly related to the joint use of international financial markets and domestic capital goods markets as consumption smoothing technologies. 

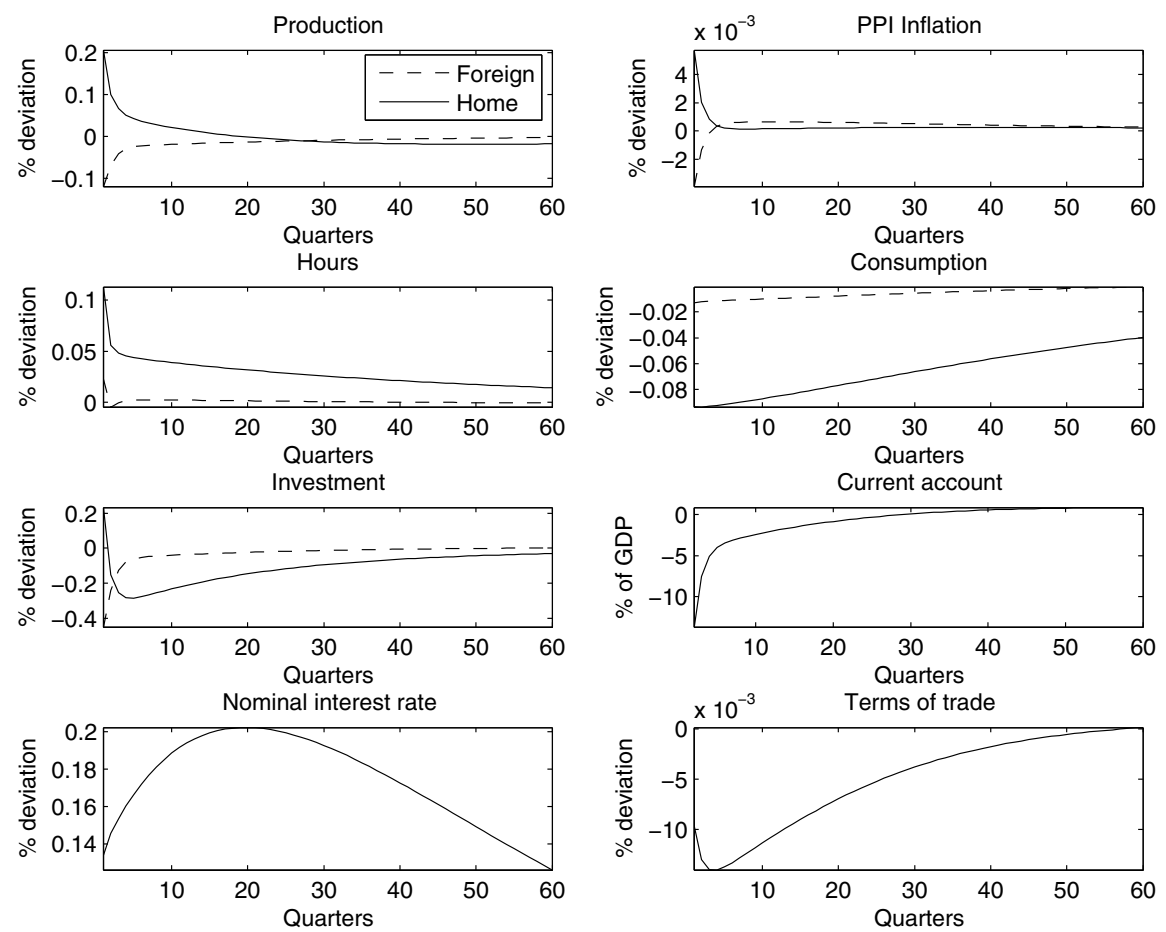

Figure 3: IRFs after a unit public spending innovation in country h.

Figure 3 presents the IRFs of most macroeconomic aggregates resulting of a $1 \%$ shock in domestic public spending. In country $h$, the production increases by $0.2 \%$ on impact, involving a significant increase of labor supply, in the stock of physical capital and in production prices. The corresponding increase in lump-sum taxes triggers a standard crowding-out effect on private consumption. As a result, the area-wide increase in demand, driven by the increase of public spending in country $h$, results in a positive area-wide inflationary stance, released by the Central Bank, that increases the nominal interest rate. As a consequence, the transmission of the shock to country $f$ occurs through the channel of the real interest rate, leading private consumption, investment and, in turn, production, to shrink. The net spillover of an increase of public spending on the foreign economy is thus characterized by the domination of the standard "beggarthy-neighbor" effect. Indeed, the positive effect on the production of country $f$ implied by trade flows from country $h$ to country $f$, and materialized by the $12 \%$ current account deficit on impact, is clearly more than compensated by the increase of the nominal interest rate. 


\section{The effects of markets integration on output and inflation dispersion}

This section evaluates the consequences of a better integration of goods and financial markets on the dispersion of business cycles and inflation rates in the monetary union.

The dispersion of business cycles $\left(\Upsilon_{\gamma, T}\right)$ and the dispersion of inflation rates $\left(\Upsilon_{\pi, T}\right)$ in the monetary union are computed according to,

$$
\Upsilon_{y, T}=\sum_{s=t}^{T}\left[E_{t}\left\{y_{s}^{h}-y_{s}^{f}\right\}^{2}\right]^{\frac{1}{2}}, \Upsilon_{\pi, T}=\sum_{s=t}^{T}\left[E_{t}\left\{\pi_{s}^{h}-\pi_{s}^{f}\right\}^{2}\right]^{\frac{1}{2}}
$$

Table 1 summarizes the consequences of a $10 \%$ increase in the value of $\varphi, \alpha, \gamma$ or a $10 \%$ reduction of $\chi$ on these two indicators. The effects are decomposed depending on the nature of shocks to appreciate their respective contribution to the global result.

These variations of $\varphi, \alpha, \gamma$ or $\chi$ can be thought of as a deeper integration of the markets for goods and services - caused for example by an exogenous reduction of trade costs (see appendix B) - or as a deeper integration of financial markets. These variations are consistent with the average estimations of Baldwin (2006) relative to the increase of commercial flows after the introduction of the euro and to those reported by Lane (2006) regarding the financial integration of the eurozone since $1999 .{ }^{10}$

\begin{tabular}{|c|c|c|c|c|c|c|c|}
\hline & I & II & $\mathrm{I}+\mathrm{II}$ & \multirow[b]{2}{*}{$\Delta \gamma=10 \%$} & I & II & $\mathrm{I}+\mathrm{II}$ \\
\hline$\Delta \alpha=10 \%$ & & & & & & & \\
\hline$\Delta \Upsilon_{y, T}$ & -1.96 & 0.52 & 0.42 & $\Delta \Upsilon_{y, T}$ & -1.01 & -5.09 & -4.86 \\
\hline$\Delta \Upsilon_{\pi, T}$ & -0.17 & 1.45 & 1.24 & $\Delta \Upsilon_{\pi, T}$ & -0.86 & -12.36 & -10.36 \\
\hline$\Delta \varphi=10 \%$ & & & & $\Delta \chi=-10 \%$ & & & \\
\hline$\Delta \Upsilon_{y, T}$ & -0.45 & -0.27 & -0.27 & $\Delta \Upsilon_{y, T}$ & 0.61 & 2.21 & 2.14 \\
\hline$\Delta \Upsilon_{\pi, T}^{3}$ & 0.23 & 0.39 & 0.40 & $\Delta \Upsilon_{\pi, T}^{3, \pi}$ & 0.14 & 3.07 & 2.63 \\
\hline
\end{tabular}

Table 1: Evolution of business cycles and inflation dispersion, in \%

Two important results emerge from Table 1. First, a deeper integration of capital and final goods markets and a deeper integration of financial markets are found to have small-scale macroeconomic effects on the dispersion of macroeconomic performances. As a matter of fact, the effect on dispersion is always 10 to 20 times lower than the corresponding increase in mar-

10 In the baseline calibration, one shall note that a $10 \%$ increase in $\alpha, \varphi$ and $\gamma$ is respectively equivalent to a $2.88 \%, 1.67 \%$ and $5.15 \%$ drop in corresponding transaction costs. 
ket integration. Moreover, a better integration of these markets may lead to an increase in the dispersion of business cycles and/or inflation (bold numbers in the table). These results demonstrate that taking into account the equilibrium of international financial markets in the long run is likely to increase the dispersion of business cycles and inflation rates. Indeed, when the external equilibrium rests more on the channel of the current account, as it is the case when the integration of final goods markets or the integration of financial markets increases, a greater dispersion of business cycles and/or inflation is often necessary to settle debts and credits in the long run in the area. This mechanism relies on compliance by the agents of their intertemporal budget constraint: debtor (resp. creditor) households need to improve (resp. reduce) their earnings to repay their debt (resp. lower their savings), which tends to increase (resp. decrease) their labor supply and their capital accumulation time profile, and results in an increase (resp. decrease) of the production of final goods. Second, a deeper integration of intermediate goods markets substantially increases the convergence of macroeconomic performances: a $10 \%$ increase in intermediate goods trade openness reduces the dispersion of business cycles by something like $5 \%$ and reduces the dispersion of inflation rates by more than $10 \%$.

In the baseline calibration, a $10 \%$ increase in final goods markets trade openness ( $\alpha$ from 0.0922 to 0.1014 ) induces an increase in the dispersion of business cycles $\left(\Upsilon_{\gamma, T}=0.42 \%\right)$. Given that the production of final goods is quite specialized across countries ( $\gamma$ is closer to 0 than to 0.5 ), macroeconomic shocks produce asymmetric effects on the production of differentiated goods. An increase in trade flows therefore leads households to use the current account more intensively to smooth their consumption across countries and states of nature. According to the mechanism described above, business cycles may disconnect to meet the equilibrium of international financial markets in the long run.

A $10 \%$ increase in capital goods markets trade openness $(\varphi$ from 0.0439 to 0.0483 ) induces a reduction in the dispersion of business cycles $\left(\Upsilon_{\gamma, T}=-0.27 \%\right)$. Indeed, an increase in capital goods trade flows induces a convergence of business cycles since capital goods are used in the production of intermediate goods, which increases the overall macroeconomic interdependence quite strongly. Simultaneously, this increase in trade flows enhances the volatility of the trade balance, which in turn reinforces the country-level asymmetries in terms of labor supply by the mechanism described previously. These asymmetries trigger asymmetries in equilibrium wages, marginal production costs and therefore inflation rates. As a result, the dispersion of inflation rates increases.

A $10 \%$ increase in intermediate goods markets trade openness implies a reduction of both inflation rates and business cycles dispersion in the monetary union. As both the composition of final goods and production 
technologies become more similar, the transmission of idiosyncratic shocks to macroeconomic variables thus becomes more symmetric, thereby dampening the need for external adjustment, and so the need for current account adjustment. So when $\gamma$ increases from 0.1646 to 0.1811 , the dispersion of business cycles is reduced by $4.86 \%$ and the the dispersion of inflation rates by $10.36 \%$.

Finally, an increase in the integration of financial markets, proxied by a $10 \%$ cut in portfolio intermediation costs $(\chi)$, increases the incentive to adjust asymmetric shocks through the channel of the current account, which amplifies the dispersion of business cycles (more especially in the case of public spending shocks) and enhances the dispersion of inflation rates.

Thus, for realistic parameters values, the integration of capital goods, final goods, and financial markets does not significantly reduce the dispersion of macroeconomic performances in a monetary union. Two competing forces are identified: $(i)$ the transmission of idiosyncratic shocks from a country to another is enhanced through trade linkages when markets integration (openness) increases but (ii) the corresponding increase in trade flows renders the trade balance and the current account more volatile, which tends to reinforce the dispersion of business cycles and inflation rates. In many cases, the latter effect dominates and an increase in the dispersion of business cycles and inflation rates can therefore arise after an increase of markets integration within a monetary union. This may explain the relative lack of convergence of macroeconomic performance observed in the euro area since 1999 .

\section{$5 \quad$ Sensitivity analysis}

In this section, we investigate the robustness of our results when structural parameters vary. Many parameters may play a key role in the mechanisms leading to the results. We more especially focus on the persistence of shocks, their correlation and the reaction coefficient of the interest rate rule. Since our results are totally insensitive to variations of $d_{\pi}$ and to variations in the correlation of productivity shocks, the sensitivity analysis concerning these parameters is not reported.

Figures 4 to 6 plot the increase or decrease in business cycles and inflation rates dispersion resulting from an increase in markets integration $(\varphi, \alpha$ and $\chi)$ for a spectrum of realistic values of $\rho_{a}, \rho_{g}$ and for different degrees of correlation of public spending shocks. 

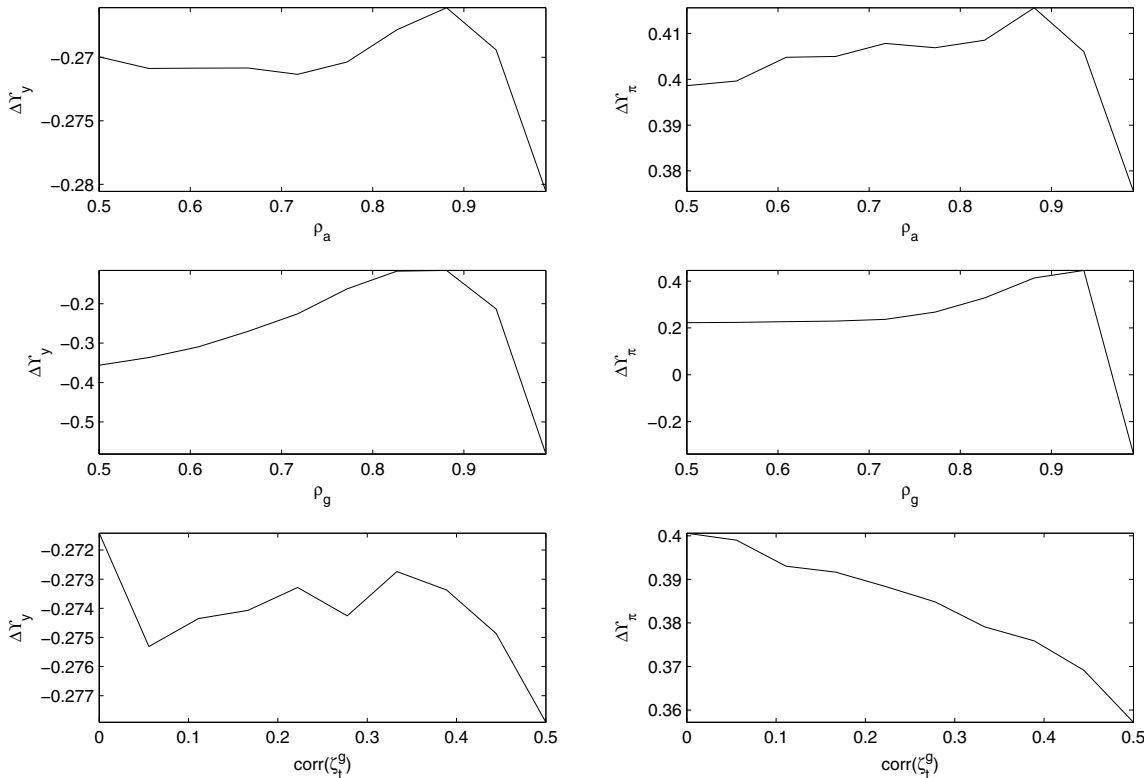

Figure 4: Effect of an increase of $\varphi$ - sensitivity.

The effects of final goods markets integration (a 10\% increase of $\alpha$ ) and financial integration (a $10 \%$ reduction of $\chi$ ) exhibit very similar patterns when key parameters vary (Figure 5 and 6 ). When productivity shocks become more persistent ( $\rho_{a}$ increases), households are less likely to use financial markets - and thus the current account - to smooth the consequences of macroeconomic shocks over time. The terms-of-trade then play a greater role in adjustment to the new situation that tends to become permanent. As a result, the dispersion of business cycles and inflation rates increases less. When public spending shocks become more persistent ( $\rho_{g}$ increases), the dispersion of business cycles and inflation rates is magnified. This effect is directly related to the fact that public spending are fully home biased, which tends to increase macroeconomic asymmetries. Finally, when the correlation of public spending shocks increases, the dispersion of business cycles and inflation rates is significantly dampened.

The sensitivity of the effects of capital goods markets integration (a $10 \%$ increase of $\varphi$ ) is close to that of final goods markets (Figure 4). The persistence of productivity and public spending shocks tends to increase the magnitude of business cycle convergence or to reduce the magnitude of the divergence of inflation rates. Finally, the correlation of public spending shocks has little effects on the evolution of business cycles and inflation rates dispersion when $\varphi$ increases. 

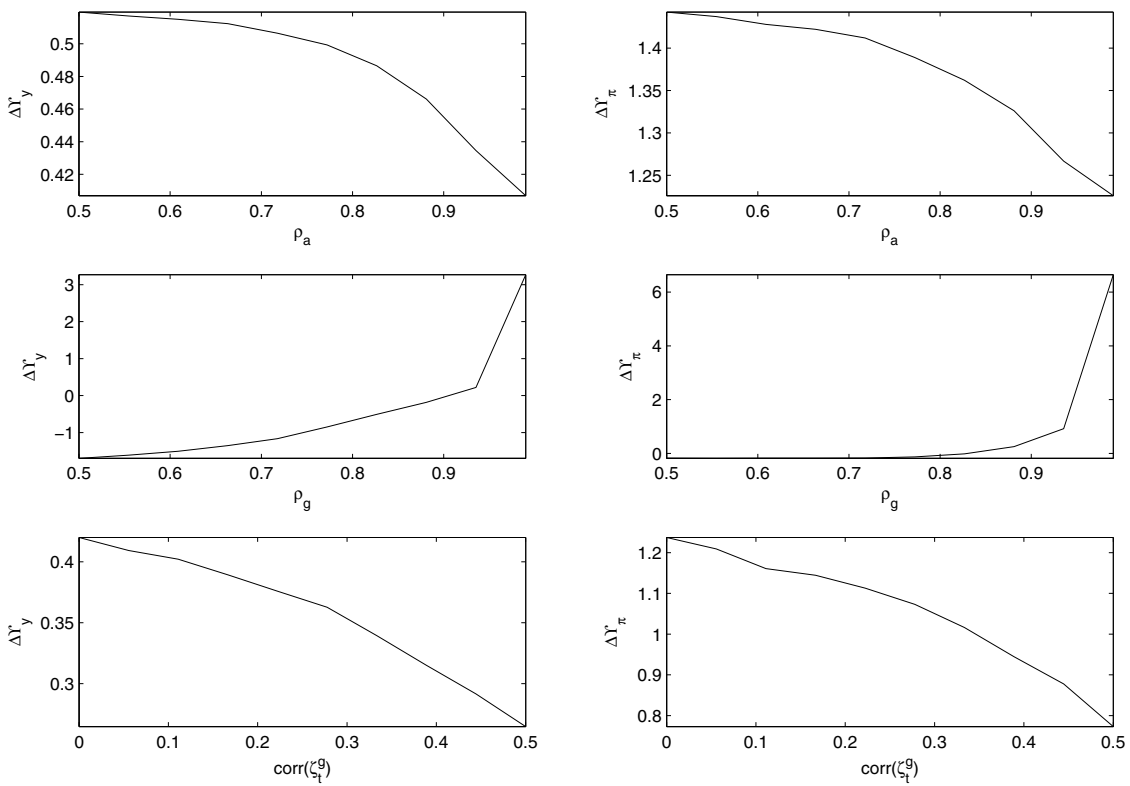

Figure 5: Effect of an increase of $\alpha$ - sensitivity.
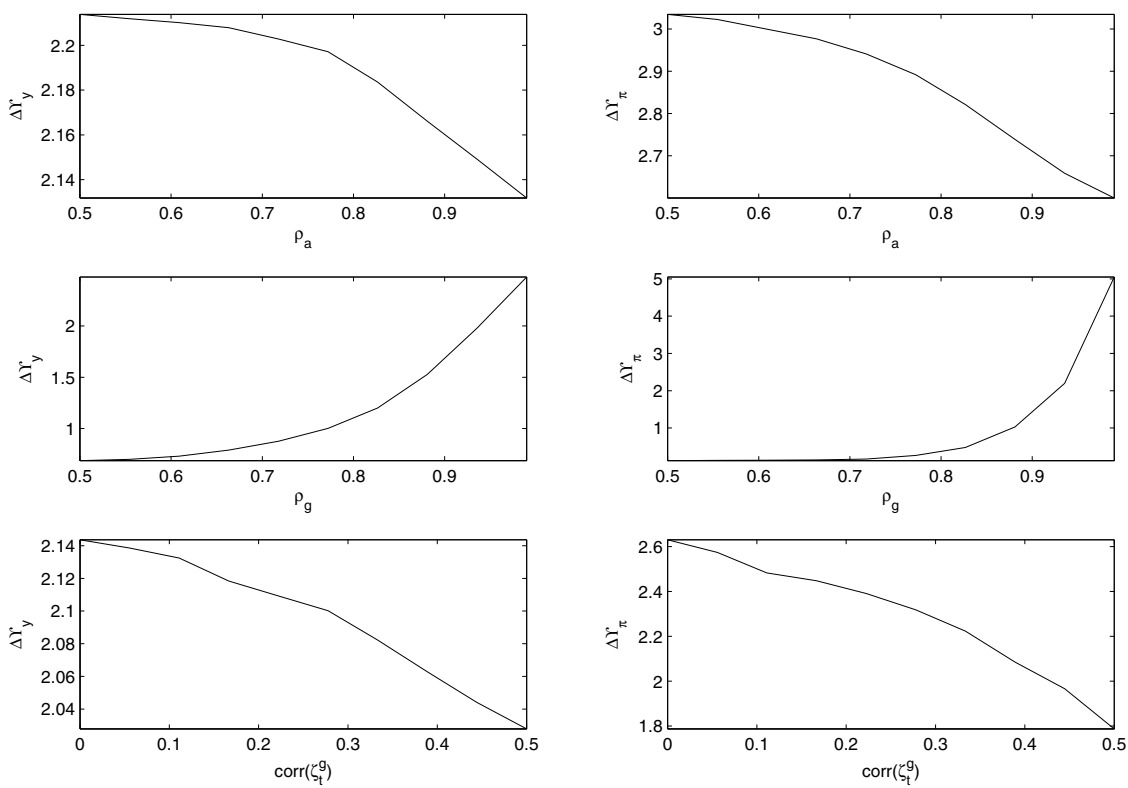

Figure 6: Effect of a reduction of $\chi-$ sensitivity. 
The main conclusion is that $\Delta \Upsilon_{\gamma, T}$ and $\Delta \Upsilon_{\pi, T}$ do not vary much when deep parameters vary and remain small-scale. In most cases, the signs of $\Delta \Upsilon_{\gamma, T}$ and $\Delta \Upsilon_{\pi, T}$ do not change, indicating that neither the degree of persistence of shocks, or their degrees of correlation are likely to fundamentally alter the results presented in the previous section.

\section{Conclusion}

This article has shown that a deeper integration of goods and financial markets does not necessarily reduce the dispersion of business cycles and inflation rates within a monetary union such as the EMU. Two key results emerge from this article.

First, an increase in the integration of final goods, capital goods and financial markets - proxied by a reduction of home bias in consumption and investment or by a reduction of portfolio intermediation costs - may lead to an increase of the dispersion of business cycles and inflation rates. This result is based on the interaction between home bias in private consumption or capital accumulation and the incompleteness of financial markets, that magnifies the role played by the current account in the adjustment to idiosyncratic shocks. After an increase in the integration of capital goods, final goods or financial markets, the magnitude current account fluctuations increases, which triggers asymmetries across output levels and inflation rates in the monetary union to reach the financial equilibrium in the long run.

On the other hand, a deeper integration of production processes proxied by a reduction of home bias in production - significantly reduces the dispersion of business cycles and inflation rates within the monetary union.

These results are obtained in a framework that is quantitatively consistent with the situation of EMU countries. They provide a plausible explanation of the fact that the dispersion of business cycles and inflation rates did not fall significantly in the EMU after the euro was introduced in 1999, in spite of an increase in mutual trade openness and in financial markets integration.

\section{References}

Angeloni, I., Aucremanne, L., Ehrmann, M., Galí, J. \& A. Levin, F. S. (2006), "New Evidence on Inflation Persistence and Prices Stickiness : Implications for Macro Modelling", Journal of the European Economic Association, Vol. 4, No2-3, pp. 562-574.

Backus, D. K., Kehoe, P. J. \& Kydland, F. E. (1993), "International Real Business Cycles: Theory vs. Evidence", Federal Reserve Bank of Minneapolis Quarterly Review, Vol. 17, pp. 14-29. 
Baldwin, R. (2006), "The Euro's Trade Effects", ECB Working Paper N594.

Beetsma, R. M. W. J. \& Jensen, H. (2005), "Monetary and Fiscal Policy Interactions in a Micro-founded Model of Monetary Union", Journal of International Economics, Vol. 67, $\mathrm{N}^{\circ} 2$, pp. 320-352.

Benigno, P. (2004), "Optimal Monetary Policy in a Currency Area", Journal of International Economics, Vol. 63, N², pp. 293-320.

Benigno, P. \& Woodford, M. (2005), "Inflation Stabilization ans Welfare: The Case of a Distorted Steady State", Journal of the European Economic Association, Vol. 3, Nº6, pp.1185-1236.

Bergin, P. R., Shin, H.-C. \& Tchakarov, I. (2007), "Does Exchange Rate Variability Matter for Welfare? A Quantitative Investigation of Stabilization Policies", European Economic Review, Vol. 51, N4, pp. 1041-1058.

Blanchard, O. J. \& Giavazzi, F. (2002), "Current Account Deficits in the Euro Area: The End of the Feldstein-Horioka Puzzle?", Brookings Papers on Economic Activity, Vol. 33, N²002-2, pp. 147-186.

Calvo, G. (1983), "Staggered Prices in a Utility-maximizing Framework", Journal of Monetary Economics, Vol. 12, N³, pp. 383-398.

Camacho, M., Perez-Quiros, G. \& Saiz, L. (2006), "Are European Business Cycles Close Enough to Be Just One?", Journal of Economics Dynamics and Control, Vol. 30, N9-10, pp. 1687-1706.

Canzoneri, M., Cumby, R. \& Diba, B. (2007), "The Cost of Nominal Inertia in NNS Models", Journal of Money, Credit and Banking, Vol. 39, Nº ${ }^{\circ}$ pp. 1563-1586.

Coeurdacier, N. (2008), "Do Trade Costs in Goods Market Lead to Home Bias in Equities?", Journal of International Economics, Vol. 77, №1, pp 86-100.

Corsetti, G. (2006), "Openness and the Case for Flexible Exchange Rates", Research in Economics, Vol. 60, $\mathrm{N}^{\circ} 1$, pp. 1-21.

De Grauwe, P. \& Mongelli, F. P. (2005), "Endogeneities of Optimum Currency Areas: What Brings Countries Sharing a Single Currency Closer Together?", ECB Working Paper $\mathrm{N}^{\circ} 468$.

Dellas, H. \& Tavlas, G. (2005), "Wage Rigidity and Monetary Union", Economic Journal, Vol. 115, N506, pp. 907-927.

Hairault, J.-O. (2002), "Labor-market Search and International Business Cycles", Review of Economic Dynamics, Vol. 5, N³, pp. 535-558.

Honohan, P. \& Lane, P. R. (2003), "Divergent Inflation Rates in EMU", Economic Policy, Vol 18, N³7, pp. 357-394.

Lane, P. R. (2006), "The Real Effects of the Euro", Journal of Economic Perspectives, Vol. 20, N4, pp. 47-66.

Monacelli, T. \& Perotti, R. (2009), "Fiscal Policy, the Real Exchange Rate, and Traded Goods", Economic Journal, forthcoming.

Obstfeld, M. \& Rogoff, K. (2000), The Six Major Puzzles in International Macroeconomics: Is there a Common Cause?, in B. Bernanke \& K. Rogoff, eds, 'NBER Macroeconomics manual 2000'.

Schmitt-Grohé, S. \& Uribe, M. (2003), "Closing Small Open Economy Models", Journal of International Economics, Vol. 61, $\mathrm{N}^{\circ} 1$, pp. 163-185. 


\section{Appendix}

\section{A The model}

\section{A.1 Households}

Each country $i \in\{h, f\}$ is populated by a unit mass of households. The representative household $j \in[0,1]$ living in nation $i$ maximizes its welfare index $^{11}$,

$$
E_{0} \sum_{s=t}^{\infty} \beta^{s-t}\left\{\frac{C_{s}^{i}(j)^{1-\rho}}{1-\rho}-\frac{N_{s}^{i}(j)^{1+\psi}}{1+\psi}\right\} .
$$

subject to the following budget constraint,

$$
\begin{aligned}
P_{t}^{i}\left(C_{t}^{i}(j)+I_{t}^{i}(j)+A C_{k, t}^{i}\right)+B_{t+1}^{i}(j)+P_{i, t} A C_{t}^{i}(j) & =W_{t}^{i} N_{t}^{i}(j)+Z_{t}^{i} K_{t}^{i}(j) \\
& +\Pi_{t}^{i}(j)+R_{t} B_{t}^{i}(j)-T_{t}^{i}(j),
\end{aligned}
$$

and the following transversality condition $\lim _{T \rightarrow \infty} \prod_{\tau=t}^{T} R_{\tau}^{-1} E_{t}\left\{B_{T+1}^{i}(j)\right\}=0$.

In these expressions, $C_{t}^{i}(j)$ is the aggregate consumption of household $j, N_{t}^{i}(j)$ its labor supply, $\rho$ the degree of risk-aversion, $\psi^{-1}$ the elasticity of its labor supply. $I_{t}^{l}(j)$, its aggregate investment in physical capital for period $t$ is defined as,

$$
I_{t}^{i}(j)=K_{t+1}^{i}(j)-(1-\delta) K_{t}^{i}(j)
$$

$W_{t}^{i}$ is the nominal wage in country $i, Z_{t}^{i}$ the nominal rent of physical capital charged by households to firms using the stock of physical capital to produce intermediate goods, $\Pi_{t}^{i}(j)$ is the dividend paid by final goods producers to household $j . B_{t}^{i}(j)$ is the amount of one-period bonds hold by household $j$ at the end of period $t-1$ paying a nominal interest rate $R_{t}$ between $t-1$ and $t, T_{t}^{i}(j)$ is a lump-sum tax, $P_{t}^{i}$ is the consumption price index in country $i$ at time $t$ and $P_{i, t}$ the production price index. In the constraint of households, $A C_{t}^{i}(j)$ is a portfolio intermediation cost such as,

$$
A C_{t}^{i}(j)=\frac{\chi}{2}\left(B_{t+1}^{i}(j)-B^{i}(j)\right)^{2},
$$

where $B^{i}(j)$ is the steady state level of assets hold by household $j$. In addition to this cost, $A C_{k, t}^{i}(j)$ is an adjustment cost bearing on a physical capital accumulation, defined as,

$$
A C_{k, t}^{i}(j)=\frac{\varepsilon}{2}\left(K_{t+1}^{i}(j)-K_{t}(j)\right)^{2} .
$$

11 We abstract from introducing real balances in the utility function since monetary policy is being conducted through a standard Taylor-type rule. 
Given households' preferences, the labor supply function is standard,

$$
N_{t}^{i}(j)^{\psi}=\frac{W_{t}^{i}}{P_{t}^{i} C_{t}^{i}(j)^{\rho}} .
$$
tions,

The presence of portfolio intermediation costs affects the Euler equa-

$$
\frac{\beta R_{t+1}}{1+\chi P_{i, t}\left(B_{t+1}^{i}(j)-B^{i}(j)\right)} E_{t}\left\{\frac{P_{t}^{i} C_{t}^{i}(j)^{\rho}}{P_{t+1}^{i} C_{t+1}^{i}(j)^{\rho}}\right\}=1,
$$

and the no-arbitrage condition among the menu of assets,

$$
E_{t}\left\{\frac{P_{t+1}^{i}}{P_{t}^{i}}\left(\frac{Z_{t+1}^{i}}{P_{t+1}^{i}}+Q_{t+1}^{i}(j)-\delta\right)\right\}=\frac{Q_{t}^{i}(j) R_{t+1}}{1+\chi P_{i, t}\left(B_{t+1}^{i}(j)-B^{i}(j)\right)},
$$

where $Q_{t}^{i}(j)$ is Tobin's $q$,

$$
Q_{t}^{i}(j)=1+\varepsilon\left(K_{t+1}^{i}(j)-K_{t}(j)\right)
$$

Aggregate consumption indexes are,

$$
C_{t}^{i}(j)=\left[\left(1-\alpha_{i}\right)^{\frac{1}{\mu}} C_{h, t}^{i}(j)^{\frac{\mu-1}{\mu}}+\left(\alpha_{i}\right)^{\frac{1}{\mu}} C_{f, t}^{i}(j)^{\frac{\mu-1}{\mu}}\right]^{\frac{\mu}{\mu-1}},
$$

and their prices,

$$
P_{t}^{i}=\left\lceil\left(1-\alpha_{i}\right)\left(P_{h, t}^{i}\right)^{1-\mu}+\left.\left(\alpha_{i}\right)\left(P_{f, t}^{i}\right)^{1-\mu}\right|^{\frac{1}{1-\mu}} .\right.
$$

In this expression, $P_{h, t}^{i}$ is the price in country $i$ of final goods produced in country $h$ and $\left(1-\alpha_{i}\right) \in\left[\frac{1}{2}, 1\right]$ is the bias in favor of domestically produced goods in economy $i$. The parameter $\mu \geq 1$ is the elasticity of substitution between final goods of country $h$ and $f$ and $C_{h, t}^{i}(k, j)$ (resp. $\left.C_{f, t}^{i}(k, j)\right)$ is the consumption of a typical variety $k$ produced in country $h$ (resp. f) of the representative household $j$ of country $i$, with,

$$
C_{h, t}^{i}(j)=\left[\int_{0}^{1} C_{h, t}^{i}(k, j)^{\frac{\theta-1}{\theta}} d k\right]^{\frac{\theta}{\theta-1}}, C_{f, t}^{i}(j)=\left[\int_{0}^{1} C_{f, t}^{i}(k, j)^{\frac{\theta-1}{\theta}} d k\right]^{\frac{\theta}{\theta-1}},
$$

where $\theta>1$ is the elasticity of substitution among varieties. Corresponding price indexes are,

$$
P_{h, t}^{i}=P_{h, t}=\left[\int_{0}^{1} P_{h, t}(k)^{1-\theta} d k\right]^{\frac{1}{1-\theta}}, P_{f, t}^{i}=P_{f, t}=\left[\int_{0}^{1} P_{f, t}(k)^{1-\theta} d k\right]^{\frac{1}{1-\theta}},
$$

and variety demands are given by,

$$
C_{h, t}^{i}(k, j)=\left(1-\alpha_{i}\right)\left[\frac{P_{h, t}}{P_{t}^{i}}\right]^{-\mu}\left[\frac{P_{h, t}(k)}{P_{h, t}}\right]^{-\theta} C_{t}^{i}(j),
$$




$$
C_{f, t}^{i}(k, j)=\alpha_{i}\left[\frac{P_{f, t}}{P_{t}^{i}}\right]^{-\mu}\left[\frac{P_{f, t}(k)}{P_{f, t}}\right]^{-\theta} C_{t}^{i}(j) .
$$

Physical capital adjustment costs are paid in terms of units of final goods and imply the following variety demands,

$$
\begin{gathered}
A C_{k, h, t}^{i}(k, j)=\left(1-\alpha_{i}\right)\left[\frac{P_{h, t}}{P_{k, t}^{i}}\right]^{-\mu}\left[\frac{P_{h, t}(k)}{P_{h, t}}\right]^{-\theta} A C_{k, t}^{i}(j), \\
A C_{k, f, t}^{i}(k, j)=\alpha_{i}\left[\frac{P_{f, t}}{P_{k, t}^{i}}\right]^{-\mu}\left[\frac{P_{f, t}(k)}{P_{f, t}}\right]^{-\theta} A C_{k, t}^{i}(j) .
\end{gathered}
$$

The definition of investment bundles is close to the definition of private consumption bundles, but differs in the degree of home bias, denoted by $1-\varphi_{i}$. The demands for final goods varieties is thus given by,

$$
\begin{gathered}
I_{h, t}^{i}(k, j)=\left(1-\varphi_{i}\right)\left[\frac{P_{h, t}}{P_{k, t}^{i}}\right]^{-\mu}\left[\frac{P_{h, t}(k)}{P_{h, t}}\right]^{-\theta} I_{t}^{i}(j), \\
I_{f, t}^{i}(k, j)=\varphi_{i}\left[\frac{P_{f, t}}{P_{k, t}^{i}}\right]^{-\mu}\left[\frac{P_{f, t}(k)}{P_{f, t}}\right]^{-\theta} I_{t}^{i}(j),
\end{gathered}
$$

where,

$$
P_{k, t}^{i}=\left[\left(1-\varphi_{i}\right)\left(P_{h, t}^{i}\right)^{1-\mu}+\left(\varphi_{i}\right)\left(P_{f, t}^{i}\right)^{1-\mu}\right]^{\frac{1}{1-\mu}} .
$$

Finally, portfolio intermediation costs are paid in terms of domestic final goods only, i.e. $A C_{t}^{i}(j)=\left[\int_{0}^{1} A C_{t}^{i}(k, j)^{\frac{\theta-1}{\theta}} d k\right]^{\frac{\theta}{\theta-1}}$, and imply the following variety demands,

$$
A C_{t}^{i}(k, j)=\left[\frac{P_{i, t}(k)}{P_{i, t}}\right]^{-\theta} A C_{t}^{i}(j)
$$

\section{A.2 Governments}

The budget constraint of country $i \in\{h, f\}$ government writes,

$$
\int_{0}^{1} T_{t}^{i}(j) d j+\tau \int_{0}^{1} P_{i, t}(k) Y_{t}^{i}(k) d k=P_{i, t} G_{t}^{i}
$$

where $G_{t}^{i}$ is the level of public spending, evolving according to,

$$
G_{t+1}^{i}=\left(1-\rho_{g}\right) G^{i}+\rho_{g} G_{t}^{i}+\zeta_{t}^{g i} .
$$

It is assumed that public spending are entirely home biased, so that,

$$
G_{t}^{i}=\left[\int_{0}^{1} G_{t}^{i}(k)^{\frac{\theta-1}{\theta}} d k\right]^{\frac{\theta}{\theta-1}} .
$$


Public spending thus give rise to the following variety demands,

$$
G_{t}^{i}(k)=\left[\frac{P_{i, t}(k)}{P_{i, t}}\right]^{-\theta} G_{t}^{i}
$$

\section{A.3 Firms}

The goods market is made of two components: (i) intermediate goods, produced and sold on perfect competition (factors and output) markets and (ii) final goods and services, produced on monopolistic competition markets.

Each country $i \in\{h, f\}$ is specialized in the production of an homogeneous intermediate good according to the following production technology,

$$
X_{t}^{i}=A_{t}^{i}\left(K_{t}^{i}\right)^{\omega}\left(L_{t}^{i}\right)^{1-\omega},
$$

where $A_{t}^{i}$ is the total factor productivity evolving according to,

$$
A_{t+1}^{i}=\left(1-\rho_{a}\right) A^{i}+\rho_{a} A_{t}^{i}+\zeta_{t}^{a i},
$$

and $K_{t}^{i}=\int_{0}^{1} K_{t}^{i}(j) d j$.

Each good is sold at the following unit price (equal to the marginal production cost),

$$
P_{x, t}^{i}=\frac{\left(Z_{t}^{i}\right)^{\omega}\left(W_{t}^{i}\right)^{1-\omega}}{\omega^{\omega}(1-\omega)^{1-\omega} A_{t}^{i}}
$$

These relations imply that factor prices satisfy,

$$
\begin{gathered}
\omega P_{x, t}^{i} X_{t}^{i}=Z_{t}^{i} K_{t}^{i}, \\
(1-\omega) P_{x, t}^{i} X_{t}^{i}=W_{t}^{i} L_{t}^{i} .
\end{gathered}
$$

In each country $i \in\{h, f\}$ a unit mass of firms produce final goods and services combining home and foreign intermediate goods. Each variety of final good is denoted $k \in[0,1]$. Each firm offers the amount $Y_{t}^{i}(k)$ of variety $k$ with the following production technology,

$$
Y_{t}^{i}(k)=\left[\left(1-\gamma_{i}\right)^{\frac{1}{\phi}} X_{h, t}^{i}(k)^{\frac{\phi-1}{\phi}}+\left(\gamma_{i}\right)^{\frac{1}{\phi}} X_{f, t}^{i}(k)^{\frac{\phi-1}{\phi}}\right]^{\frac{\phi}{\phi-1}} .
$$

The corresponding marginal cost is given by,

$$
C M_{t}^{i}(k)=C M_{t}^{i}=\left[\left(1-\gamma_{i}\right)\left(P_{x, t}^{h}\right)^{1-\phi}+\left(\gamma_{i}\right)^{\frac{1}{\phi}}\left(P_{x, t}^{f}\right)^{1-\phi}\right]^{\frac{1}{1-\phi}}
$$

In these expressions, $\left(1-\gamma_{i}\right) \in\left[\frac{1}{2}, 1\right]$ is the bias in favor of the domestic input and $\phi$ is the elasticity of substitution among home and foreign 
intermediate goods. $X_{h, t}^{i}(k)$ and $X_{f, t}^{i}(k)$ stand for demands of intermediate goods $h$ and $f$ from the final producer of variety $k$ located in country $i$,

$$
X_{h, t}^{i}(k)=\left(1-\gamma_{i}\right)\left[\frac{P_{x, t}^{h}}{C M_{t}^{i}}\right]^{-\phi} Y_{t}^{i}(k), X_{f, t}^{i}(k)=\gamma_{i}\left[\frac{P_{x, t}^{f}}{C M_{t}^{i}}\right]^{-\phi} Y_{t}^{i}(k) .
$$

The representative final variety $k$ producer maximizes its profits,

$$
\Pi_{t}^{i}(k)=\left((1-\tau) P_{i, t}(k)-C M_{t}^{i}\right) Y_{t}^{i}(k),
$$

given the total variety demand,

$Y_{t}^{i}(k)=\left[\frac{P_{i, t}(k)}{P_{i, t}}\right]^{-\theta}\left[C_{i, t}^{h}+C_{i, t}^{f}+A C_{k, i, t}^{h}+A C_{k, i, t}^{f}+I_{i, t}^{h}+I_{i, t}^{f}+G_{t}^{i}+A C_{t}^{i}\right]$,

with,

$$
\begin{gathered}
C_{h, t}^{i}=\int_{0}^{1} C_{h, t}^{i}(j) d j, C_{f, t}^{i}=\int_{0}^{1} C_{f, t}^{i}(j) d j, \\
I_{h, t}^{i}=\int_{0}^{1} I_{h, t}^{i}(j) d j, I_{f, t}^{i}=\int_{0}^{1} I_{f, t}^{i}(j) d j, \\
A C_{k, h, t}^{i}=\int_{0}^{1} A C_{k, h, t}^{i}(j) d j, A C_{k, f, t}^{i}=\int_{0}^{1} A C_{k, f, t}^{i}(j) d j, \\
\text { and } A C_{t}^{i}=\int_{0}^{1} A C_{t}^{i}(j) d j .
\end{gathered}
$$

Calvo (1983) contracts lead final producers allowed to reset their prices to solve,

$$
\underset{P_{i, t}(k)}{\operatorname{Arg} \max } \sum_{v=0}^{\infty}\left(\eta^{i} \beta\right)^{v} E_{t}\left\{\frac{Y_{t+\nu}^{i}(k)}{P_{t+\nu}^{i} C_{t+\nu}^{i}(j)^{\rho}}\left[(1-\tau) P_{i, t}(k)-C M_{t+\nu}^{i}\right]\right\} .
$$

The corresponding optimal reset price $\bar{P}_{i, t}(k)$ is thus given by,

$$
\bar{P}_{i, t}(k)=\frac{\theta}{(\theta-1)(1-\tau)} \frac{\sum_{v=0}^{\infty}\left(\eta^{i} \beta\right)^{v} E_{t}\left\{\left(Y_{t+\nu}^{i}(k) C M_{t+\nu}^{i}\right) /\left(P_{t+\nu}^{i} C_{t+\nu}^{i}(j)^{\rho}\right)\right\}}{\sum_{v=0}^{\infty}\left(\eta^{i} \beta\right)^{v} E_{t}\left\{Y_{t+\nu}^{i}(k) /\left(P_{t+\nu}^{i} C_{t+\nu}^{i}(j)^{\rho}\right)\right\}} .
$$

Aggregating among final producers, the average production price level of final goods and services in country $i$ is,

$$
P_{i, t}=\left[\left(1-\eta^{i}\right) \bar{P}_{i, t}(k){ }^{1-\theta}+\eta^{i} P_{i, t-1}^{1-\theta}\right]^{\frac{1}{1-\theta}} .
$$




\section{A.4 General equilibrium}

The model is solved under the assumption that,

$$
\begin{aligned}
\alpha_{h} & =\alpha \text { implying } \alpha_{f}=(1-\alpha), \\
\varphi_{h} & =\varphi \text { implying } \varphi_{f}=(1-\varphi), \\
\gamma_{h} & =\gamma \text { implying } \gamma_{f}=(1-\gamma),
\end{aligned}
$$

and defining the aggregate production bundles in country $i$ as,

$$
Y_{t}^{i}=\left[\int_{0}^{1} Y_{t}^{i}(k)^{\frac{\theta-1}{\theta}} d k\right]^{\frac{\theta}{\theta-1}} .
$$

An equilibrium is defined as a sequence of prices:

$\left\{\mathcal{P}_{t}\right\}_{t=0}^{\infty}=\left\{W_{t}^{h}, W_{t}^{f}, Z_{t}^{h}, Z_{t}^{f}, P_{x, t}^{h}, P_{x, t}^{f}, C M_{t}^{h}, C M_{t}^{f}, \bar{P}_{h, t}(k), \bar{P}_{f, t}(k), P_{h, t}, P_{f, t}, P_{t}^{h}, P_{t}^{f}, P_{k, t}^{h}, P_{k, t}^{f}\right\}_{t=0}^{\infty}$, a sequence of quantities:

$\left\{\mathcal{Q}_{t}\right\}_{t=0}^{\infty}=\left\{Y_{t}^{h}, Y_{t}^{f}, C_{t}^{h}, C_{t}^{f}, I_{t}^{h}, I_{t}^{f}, K_{t}^{h}, K_{t}^{f}, L_{t}^{h}, L_{t}^{f}, N_{t}^{h}, N_{t}^{f}, B_{t}^{h}, B_{t}^{f}, A C_{t}^{h}, A C_{t}^{f}, A C_{k, t}^{h}, A C_{k, t}^{f}\right\}_{t=0}^{\infty}$, and a monetary policy rule:

$$
\left\{R_{t+1}\right\}_{t=0}^{\infty}
$$

such that:

(i) For a given sequence $\left\{P_{t}\right\}_{t=0}^{\infty}$, a sequence of shocks $\left\{S_{t}\right\}_{t=0}^{\infty}=\left\{A_{t}^{h}, A_{t}^{f}\right.$, $\left.G_{t}^{h}, G_{t}^{f}\right\}_{t=0}^{\infty}$ and a monetary policy $\left\{R_{t+1}\right\}_{t=0}^{\infty},\left\{Q_{t}\right\}_{t=0}^{\infty}:$

- solves households programs by satisfying equations (1)-(10),

- insures the efficiency of intermediate goods production by satisfying equations (11)-(12),

- maximizes final producers profits by verifying equations (13)-(14).

For a given sequence of quantities $\left\{Q_{t}\right\}_{t=0}^{\infty}$, a sequence of shocks $\left\{S_{t}\right\}_{t=0}^{\infty}$ and a monetary policy $\left\{R_{t+1}\right\}_{t=0}^{\infty},\left\{P_{t}\right\}_{t=0}^{\infty}$ clears:

- the labor markets,

$$
N_{t}^{i}=\int_{0}^{1} N_{t}^{i}(j) d j=L_{t}^{i}
$$

- the markets of final goods and services,

$$
\begin{aligned}
Y_{t}^{h} & =(1-\alpha)\left[\frac{P_{h, t}}{P_{t}^{h}}\right]^{-\mu}\left(C_{t}^{h}+A C_{k, t}^{h}\right)+\alpha\left[\frac{P_{h, t}}{P_{t}^{f}}\right]^{-\mu}\left(C_{t}^{f}+A C_{k, t}^{f}\right) \\
& +(1-\varphi)\left[\frac{P_{h, t}}{P_{k, t}^{h}}\right]^{-\mu} I_{t}^{h}+\varphi\left[\frac{P_{h, t}}{P_{k, t}^{f}}\right]^{-\mu} I_{t}^{f}+G_{t}^{h}+A C_{t}^{h},
\end{aligned}
$$




$$
\begin{aligned}
Y_{t}^{f} & =(1-\alpha)\left[\frac{P_{f, t}}{P_{t}^{f}}\right]^{-\mu}\left(C_{t}^{f}+A C_{k, t}^{f}\right)+\alpha\left[\frac{P_{f, t}}{P_{t}^{h}}\right]^{-\mu}\left(C_{t}^{h}+A C_{k, t}^{h}\right) \\
& +(1-\varphi)\left[\frac{P_{f, t}}{P_{k, t}^{f}}\right]^{-\mu} I_{t}^{f}+\varphi\left[\frac{P_{f, t}}{P_{k, t}^{h}}\right]^{-\mu} I_{t}^{h}+G_{t}^{f}+A C_{t}^{f},
\end{aligned}
$$

- the markets of intermediate goods,

$$
\begin{aligned}
& A_{t}^{h}\left(K_{t}^{h}\right)^{\omega}\left(L_{t}^{h}\right)^{1-\omega}=(1-\gamma)\left[\frac{P_{x, t}^{h}}{C M_{t}^{h}}\right]^{-\phi} Y_{t}^{h} D P_{h, t}+\gamma\left[\frac{P_{x, t}^{h}}{C M_{t}^{h}}\right]^{-\phi} Y_{t}^{f} D P_{f, t}, \\
& A_{t}^{f}\left(K_{t}^{f}\right)^{\omega}\left(L_{t}^{f}\right)^{1-\omega}=(1-\gamma)\left[\frac{P_{x, t}^{f}}{C M_{t}^{f}}\right]^{-\phi} Y_{t}^{f} D P_{f, t}+\gamma\left[\frac{P_{x, t}^{f}}{C M_{t}^{h}}\right]^{-\phi} Y_{t}^{h} D P_{h, t},
\end{aligned}
$$

where $D P_{i, t}=\int_{0}^{1}\left[\frac{P_{i, t}(k)}{P_{i, t}}\right]^{-\theta}$ stands for production prices dispersion in country $i$,

- the financial market,

$$
\begin{gathered}
B_{t+1}^{i}-R_{t} B_{t}^{i}=P_{x, t}^{h} X_{t}^{h}-C M_{t}^{h} Y_{t}^{h}+P_{h, t}\left(Y_{t}^{h}-G_{t}^{h}-A C_{t}^{h}\right)-P_{t}^{h}\left(C_{t}^{h}+I_{t}^{h}\right), \\
B_{s}^{h}+B_{s}^{f}=0, \forall s=t, t+1 .
\end{gathered}
$$

\section{B Iceberg costs and home bias in consumption}

We firstly express relative consumptions in a framework à la Obstfeld and Rogoff (2000). Consumption bundles are defined as,

with,

$$
\begin{aligned}
C & =\left[\left(C_{h}\right)^{\frac{\mu-1}{\mu}}+\left(C_{f}\right)^{\frac{\mu-1}{\mu}}\right]^{\frac{\mu}{\mu-1}}, \\
C^{*} & =\left[\left(C_{h}^{*}\right)^{\frac{\mu-1}{\mu}}+\left(C_{f}^{*}\right)^{\frac{\mu-1}{\mu}}\right]^{\frac{\mu}{\mu-1}},
\end{aligned}
$$

$$
\begin{gathered}
P=\left[\left(P_{h}\right)^{1-\mu}+\left(P_{f}\right)^{1-\mu}\right]^{\frac{1}{1-\mu}}, P^{*}=\left[\left(P_{h}^{*}\right)^{1-\mu}+\left(P_{f}^{*}\right)^{1-\mu}\right]^{\frac{1}{1-\mu}}, \\
P_{h}=(1-c) P_{h}^{*}, P_{f}^{*}=(1-c) P_{f}
\end{gathered}
$$

where $c \in[0,1]$ and $\mu$ is the elasticity of substitution between home and foreign goods. Home demands for home and foreign goods are then,

$$
\begin{aligned}
C_{h} & =\left(\frac{P_{h}}{P}\right)^{-\mu} C, \\
C_{f} & =\left(\frac{P_{f}}{P}\right)^{-\mu} C .
\end{aligned}
$$


Defining domestic terms-of-trade as $T=\frac{P_{f}^{*}}{P_{h}}$ and expressing relative consumptions as a function of $T$ and $c$, we get,

$$
\frac{C_{h}}{C_{f}}=\left(\frac{P_{f}}{P_{h}}\right)^{\mu}=\left(\frac{P_{f}^{*}}{P_{h}(1-c)}\right)^{\mu}=\left(\frac{T}{1-c}\right)^{\mu} .
$$

In a framework with home bias in consumption, we mimic this process. Consumption bundles are,

$$
\begin{aligned}
C & =\left[(1-\alpha)^{\frac{1}{\mu}}\left(C_{h}\right)^{\frac{\mu-1}{\mu}}+\alpha^{\frac{1}{\mu}}\left(C_{f}\right)^{\frac{\mu-1}{\mu}}\right]^{\frac{\mu}{\mu-1}}, \\
C^{*} & =\left[(1-\alpha)^{\frac{1}{\mu}}\left(C_{f}\right)^{\frac{\mu-1}{\mu}}+\alpha^{\frac{1}{\mu}}\left(C_{h}\right)^{\frac{\mu-1}{\mu}}\right]^{\frac{\mu}{\mu-1}},
\end{aligned}
$$

and corresponding price indexes are,

$$
\begin{aligned}
P & =\left[(1-\alpha)\left(P_{h}\right)^{1-\mu}+\alpha\left(P_{f}\right)^{1-\mu}\right]^{\frac{1}{1-\mu}}, \\
P^{*} & =\left[(1-\alpha)\left(P_{f}\right)^{1-\mu}+\alpha\left(P_{h}\right)^{1-\mu}\right]^{\frac{1}{1-\mu}} .
\end{aligned}
$$

Home demands for home and foreign goods are,

$$
\begin{gathered}
C_{h}=(1-\alpha)\left(\frac{P_{h}}{P}\right)^{-\mu} C, \\
C_{f}=\alpha\left(\frac{P_{f}}{P}\right)^{-\mu} C .
\end{gathered}
$$

Posing $T=\frac{P_{f}}{P_{h}}=\frac{P_{f}^{*}}{P_{h}}$ (since the law of one price holds in this monetary union setting), relative consumptions are,

$$
\frac{C_{h}}{C_{f}}=\frac{(1-\alpha)}{\alpha} T^{\mu} .
$$

In equations (15) and (16), $T$ stands for domestic terms-of-trade. We deduce the following relation between trade costs and home bias,

$$
c=1-\left[\frac{\alpha}{(1-\alpha)}\right]^{\frac{1}{\mu}} \text { or } \alpha=\frac{(1-c)^{\mu}}{1+(1-c)^{\mu}} .
$$

